UDC 621.039.623

\title{
TOKAMAKS WITH EXTERNAL X-POINTS: STABILITY LIMITS AND NEW PROSPECTS
}

\author{
S.Yu. Medvedev ${ }^{l, 2}$, A.A. Martynov ${ }^{l, 2}$, B.V. Kuteev ${ }^{l}$, A.Yu. Dnestrovskiy ${ }^{l}$, V.V. Drozdov ${ }^{3}$ \\ ${ }^{I}$ NRC «Kurchatov Institute», Moscow, Russia \\ ${ }^{2}$ Keldysh Institute of Applied Mathematics RAS, Moscow, Russia \\ ${ }^{3}$ Tokamak Energy Ltd, United Kingdom \\ This paper considers the prospects of outer X-point tokamak configurations that exhibit MHD stability properties similar to those of neg- \\ ative triangularity tokamaks. The most recent numerical studies of ideal MHD stability for outer X-point configurations provide evidence \\ of beta limits, $\beta_{N} \geq 3$, and the passive stabilization of axisymmetric modes in plasmas with an elongation close to unity. Formation of an \\ outer X-point with the help of a simple magnetic system is examined. A more general outlook on the external X-point tokamaks is of- \\ fered including power exhaust, edge stability and divertor geometry.
}

Key words: tokamak, divertor, X-points, MHD stability.

DOI: $10.21517 / 0202-3822-2021-44-2-15-20$

\section{ТОКАМАКИ С ВНЕШНИМИ Х-ТОЧКАМИ: ПРЕДЕЛЫ УСТОЙЧИВОСТИ И НОВЫЕ ВОЗМОЖНОСТИ}

\author{
С.Ю. Медведев ${ }^{1,2}$ А.А. Мартынов ${ }^{1,2}$, Б.В. Кутеев ${ }^{1}$, А.Ю. Днестровский ${ }^{1}$, В.В. Дроздов ${ }^{3}$
}

\author{
${ }^{1}$ НИЦ «Курчатовский институт», Москва, Россия \\ ${ }^{2}$ Институт прикладной математики им. М.В. Келдыма РАН, Москва, Россия \\ ${ }^{3}$ Tokamak Energy Ltd, Великобритания
}

Рассмотрены перспективы конфигураций токамаков с внешней Х-точкой, обладающих свойствами МГД-устойчивости, аналогичными конфигурациям с отрицательной треугольностью. Новые расчёты идеальной МГД-устойчивости показывают пределы по $\beta_{N} \geq 3$ и пассивную устойчивость осесимметричных мод для плазмы с вытянутостью, близкой к единице. Изучается формирование внешней $\mathrm{X}$-точки с помощью упрощённой магнитной системы. Обсуждаются более общие перспективы токамаков с внешней X-точкой, включая отвод мощности, устойчивость краевой плазмы и геометрию дивертора

Ключевые слова: токамак, дивертор, Х-точки, МГД-устойчивость.

\section{INTRODUCTION}

Power handling in magnetic plasma confinement systems is a major challenge for fusion programs around the world. The tolerance limits of steady-state and transient thermal stresses in tokamaks are constrained by different materials-engineering issues. In addition, a stationary confinement regime is required for tokamak-based reactors as well as tokamak-based fusion neutron sources. No matter how good an energy confinement is, a poorly performing power exhaust system makes a stationary machine design dysfunctional. That is why the «power exhaust first» paradigm comes up with a particular stress on the negative triangularity plasmas. Tokamak plasma with negative triangularity has been actively investigated both experimentally $[1,2]$ and theoretically, as part of plasma confinement [3] and demonstration reactor power exhaust studies [4]. Numerical studies of the ideal MHD stability for negative triangularity plasmas with X-points shifted to the outer side of the torus [5] confirmed that even in the absence of a magnetic well with elongated cross-section, stability limits imposed by external kink modes meet the reactor requirements for normalized beta $\beta_{N} \geq 3$. At the same time, plasma pressure in the pedestal near the plasma edge is about 4 times lower compared to that in conventional tokamaks with a D-shaped cross section and positive triangularity [6]. Therefore, strong ELMs (edge localized modes), unacceptable in large tokamaks, are expected to be robustly avoided.

However, some core confinement advantages observed in negative triangularity experiments, providing insight into the prospects of negative triangularity tokamaks as fusion systems, are not explained by plasma theory yet and all projections for reactor scales are very preliminary. The high energy confinement mode (H-mode) in negative triangularity diverted plasmas is still to be demonstrated. Vertical axisymmetric instabilities also pose a problem for negative triangularity plasmas with elongated cross-sections [5]. There are other new engineering challenges to overcome, including the rejection of low-stressed D-shaped toroidal field coils substituted by the coils compatible to the outer divertor with a wider separatrix wetted area at larger major radius. A more general 
question arises concerning configurations that would allow a greater plasma volume to be pushed into a domain with a lower toroidal field without changing the aspect ratio (especially relevant for spherical tokamaks): is it a necessary handicap for a stationary outboard power exhaust?

Are there other tokamak plasma configurations, which are ELM-proof and power exhaust oriented and still simple and versatile? This question opens up the pathway to consider external X-points (primarily single-outer X-point) tokamak configurations that exhibit MHD stability properties similar to those of negative triangularity tokamaks. An outer X-point divertor configuration was tested as part of the JT-60 tokamak original version (1985 - November 1989, upgraded to JT-60U (1991-2010), see [7]) with limited success: the H-mode was not properly attained with a hydrogen plasma. However, even back in the 1980's it was clear that the presence of an X-point at the torus outside did not preclude high beta values [8]. The configurations with outer $\mathrm{X}$-points and oblate cross-sections are also relevant to constant mean curvature surfaces providing maximal volume among all toroidal surfaces of a given area [9].

This paper presents new calculations of the free boundary equilibrium and ideal MHD stability for external X-point tokamaks. External kink-imposed limits for equilibria with prescribed boundary shapes are treated in the next section together with stability calculations for axisymmetric $n=0$ modes. Examples of magnetic system layouts and free boundary equilibria are given. The prospects of eXternal X-point (XX) configurations are discussed.

\section{OUTER X-POINT: MHD-STABILITY}

The KINX stability code [10] was used to calculate ideal MHD-limits for a series of equilibria with a fixed boundary parameterized as follows:

$$
\begin{gathered}
R=R_{0 \mathrm{X}}+a_{\mathrm{X}} f(\theta) \cos \theta-\delta_{\mathrm{X}} \sin ^{2} \theta, \quad Z=Z_{0}+a_{\mathrm{X}} k_{\mathrm{X}} \sin \theta,-\pi<\theta<\pi, \\
f(\theta)=1+\mathrm{X}(1-|\sin \theta|)^{p_{\mathrm{X}}}, \quad \mathrm{X}=k_{\mathrm{X}} / p_{\mathrm{X}}, k_{\mathrm{X}}=k /\left(1-0.5 k / p_{\mathrm{X}}\right), \\
a_{\mathrm{X}}=a /(1+\mathrm{X} / 2), R_{0 \mathrm{X}}=R_{0}-a_{\mathrm{X}} \mathrm{X} / 2, \delta_{\mathrm{X}}=\delta(1+\mathrm{X} / 2)-\mathrm{X} / 2 .
\end{gathered}
$$

This plasma shape features outer X-point at $R=R_{0}+a$ (the 90-degree angle between separatrix branches is provided by $\mathrm{X}=k_{\mathrm{X}} / p_{\mathrm{X}}$ ) and prescribed major and minor radii, $R_{0}$ and $a$, as well as elongation $k$ and triangularity $\delta$ (Fig. 1,a).

Given the plasma shape and initial parallel current density and pressure profiles (Fig. 1, b), the limiting pressure profile was computed against the ballooning mode stability with the current density profile kept fixed, and the pressure gradient iteratively adjusted. The resulting plasma profiles are shown in Fig. 2, $a$. The norma-
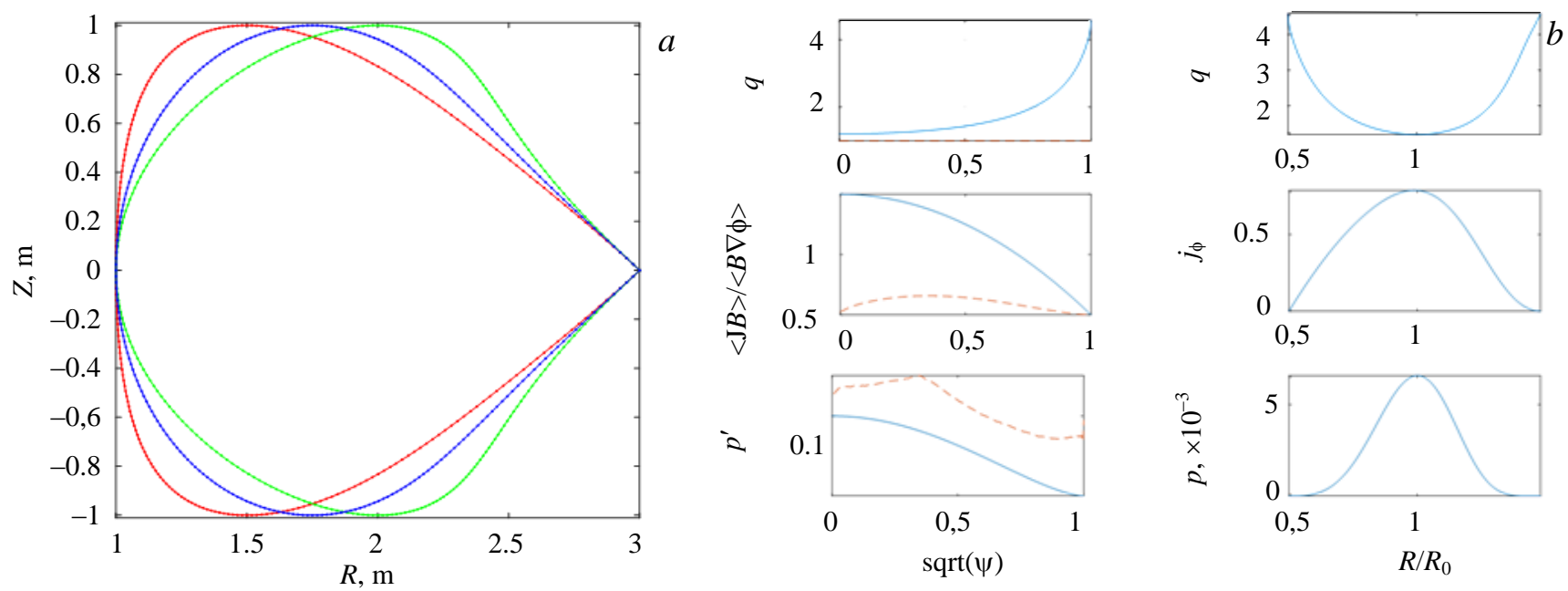

Fig. 1. Plasma shapes with outer X-point: $R_{0}=2 \mathrm{~m}, a=1 \mathrm{~m}, k=1, p_{\mathrm{X}}=2,-\longrightarrow \delta=0,--\delta=0.25 ;-\square=0.5(a)$; plasma profiles for the initial equilibrium with prescribed parallel current density and pressure gradient profiles: $\delta=0$, internal inductance $l_{i}=0.89, I_{N}=0.79, \beta_{N}=0.84(b)$; dashed lines show the bootstrap current in collision-less limit, the ballooning mode limiting pressure gradient and $q=1$ in the corresponding plots 
lized current $I_{N}=I(\mathrm{MA}) / a(\mathrm{~m}) / B(\mathrm{~T})=0.79$ where $I, a$ and $B$ are plasma current, minor radius and vacuum magnetic field at the plasma center respectively, corresponds to the safety factor $q_{95}=4.0$. The normalized beta is defined as $\beta_{N}=\left(2 \mu_{0}<p>/ B^{2}\right) / I_{N}$. One can also note a quite high bootstrap current fraction $f_{\mathrm{b}}=0.64$ (bootstrap current density in the collision-less limit is indicated by dashed line in the parallel current plot in Fig. $2, a$ ) and
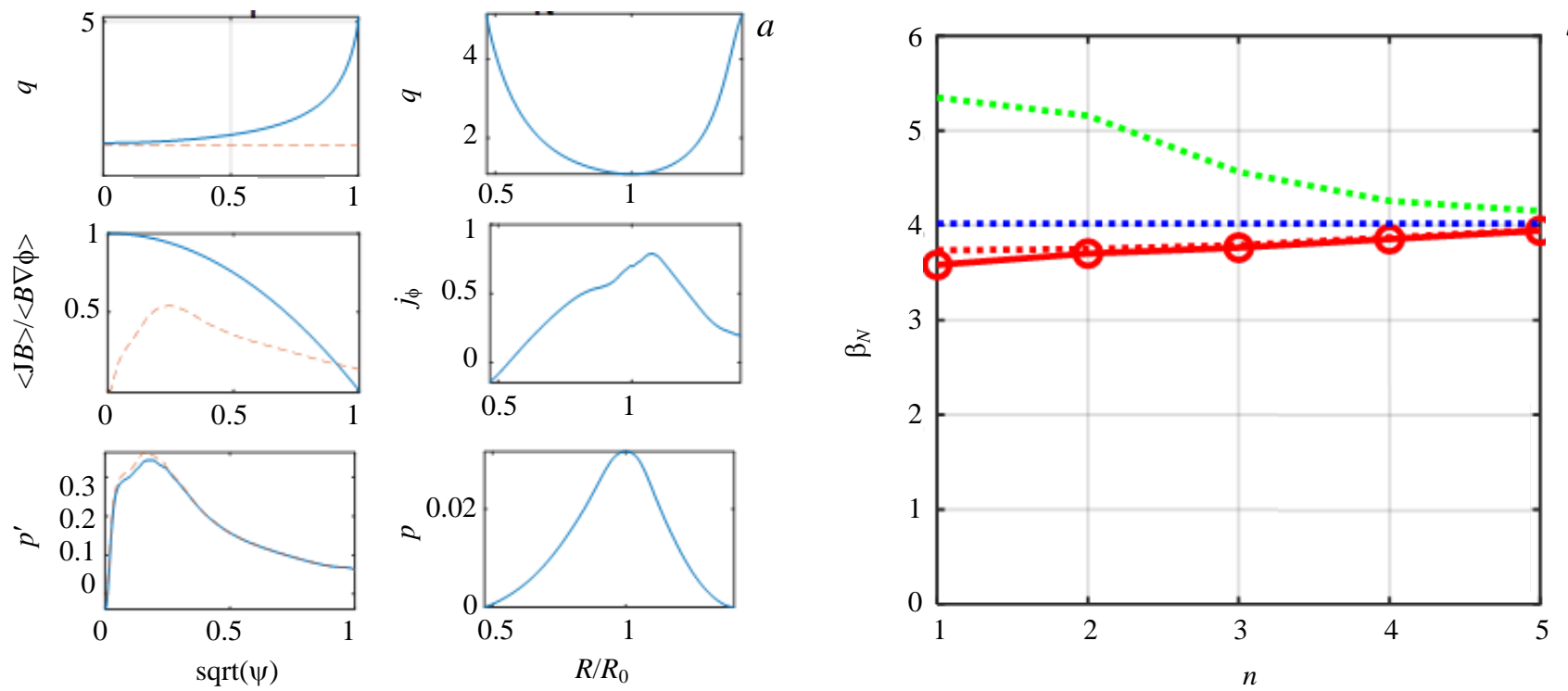

$b$
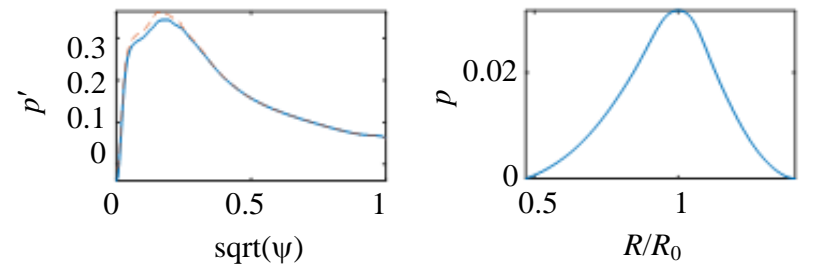

Fig. 2. Plasma profiles for the ballooning mode optimized equilibrium with prescribed parallel current: $l_{i}=0.88, I_{N}=0.79, \beta_{N}=4.02(a)$; limiting values of normalized $\beta_{N}$ for different toroidal mode numbers; no wall, conformal wall at the $1.3 a$ radius from plasma and wall at

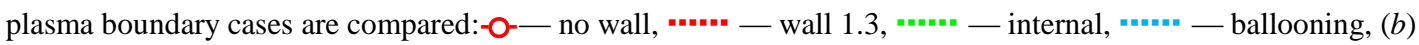

the evidence of access to the second stability region in the core (local marginally stable pressure gradient, shown in the dashed line in the corresponding plot is higher than the pressure gradient in the core). The ballooning mode optimized pressure profile was then rescaled and the marginally stable $\beta_{N}$ was determined for external kink modes with toroidal mode numbers $n$ from 1 to 5 (Fig. 2, $b$ ). The $n=1$ mode sets the overall limit $\beta_{N}=3.6$ for such an equilibrium series without wall stabilization. Only a slight increase in $\beta_{N}$ due to the presence of ideally conducting wall indicates the strong coupling between external and internal modes (for internal modes alone, i.e. with ideally conducting wall at plasma boundary, $\beta_{N}>5$ for $n=1$ ).

For edge stability calculations the core pressure gradient was multiplied by 0.6 to step back from the global mode stability boundary. Hyperbolic tangent pedestal profiles were introduced (Fig. 3, $a$ ) and then rescaled as in
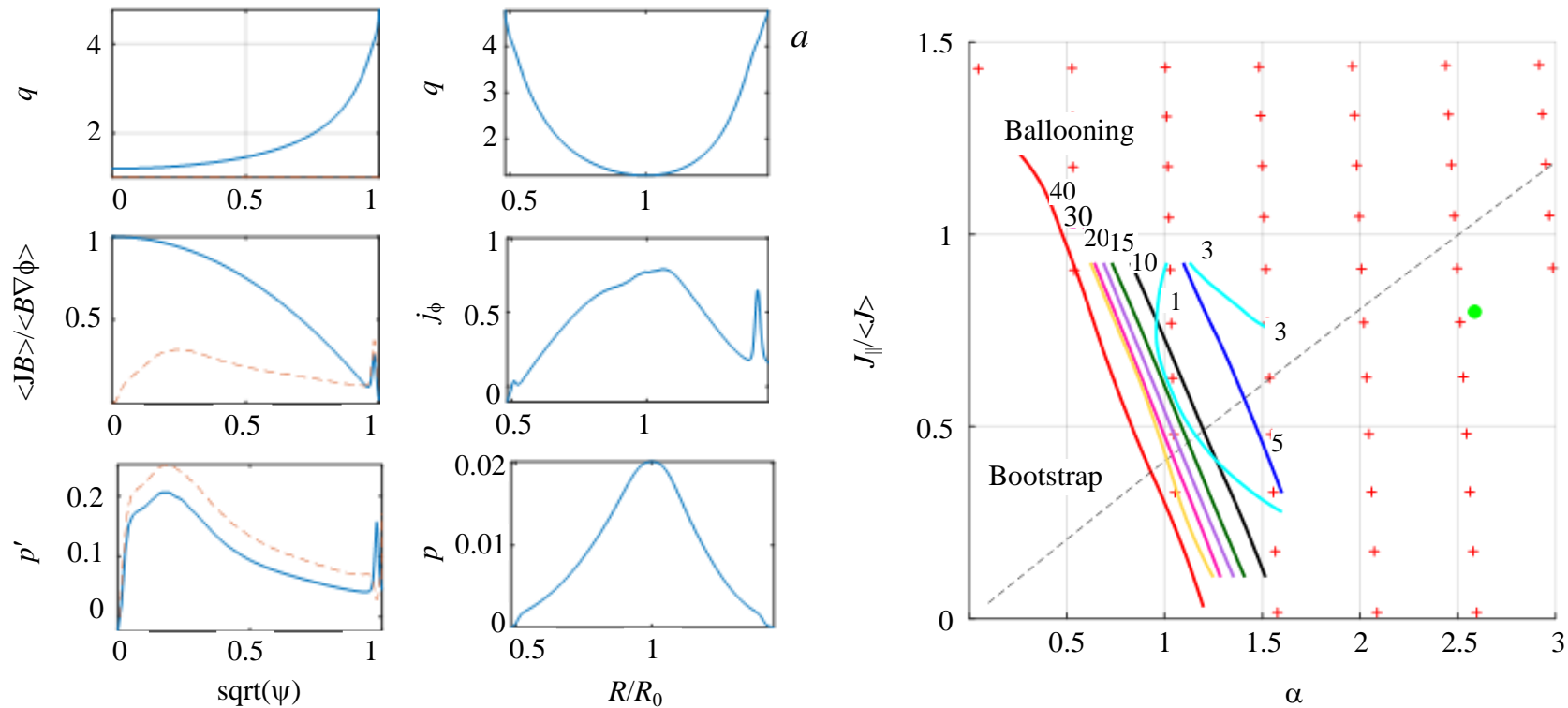

$b$
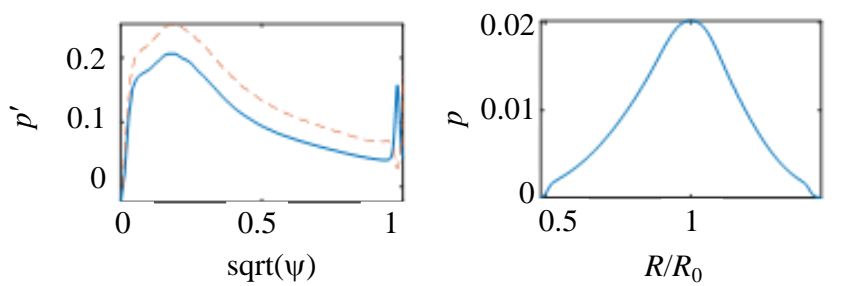

Fig. 3. Plasma profiles for the equilibrium with pedestal $\beta=0.02, I_{N}=0.79, \beta_{N}=2.56(a)$; edge stability diagram with margins for different toroidal mode numbers and ballooning modes, red crosses correspond to ballooning unstable region, green circle - parameters of initial equilibrium with pedestal, maximal pressure gradient at $\operatorname{sqrt}\left(\psi_{0}\right)=0.98, J_{\text {edge }} / J=0.071, p^{\prime}{ }_{\text {edge }} / p^{\prime}=0.284(b)$ 
[11]. The calculated edge stability diagram for the rescaled pedestal profiles is presented in Fig. $3, b$. Here $\alpha$ is the normalized pressure gradient and $J_{\|} \mid\langle J\rangle$ is the normalized parallel current density, where $\langle J\rangle=I_{p} / S_{p}$ is the average current density over plasma cross-section, they are estimated at the position of maximum pressure gradient $\mathrm{p}^{\prime}$ in the pedestal region. The pedestal limit is very low - a factor of 2.5 lower than in the initial equilibrium with pedestal (pedestal parameters are represented as the green circle). The scaling for pedestal height in ITER-like D-shape plasmas [11] $\beta_{p \text {, ped }} \approx 3 D^{3 / 4} / I_{N}^{1 / 3}$ gives the poloidal beta limit $\beta_{\mathrm{p} \text {, ped }}$ of 0.44 which is more than 5 times as large as that for the outer X-point case (0.08) for the chosen pedestal depth parameter $D=0.07$ (in normalized poloidal flux units). The remarkable thing is that internal $n=\infty$ ballooning modes go unstable first with increasing pedestal height (approximately along the bootstrap dashed line).

Axisymmetric modes $n=0$ are expected to be passively stable (without wall stabilization) for the XX-equilibria with an elongation of 1 . This is indeed the case of the equilibrium with plasma profiles shown in Fig. 1, $b$ with the pressure gradient going to zero at the plasma boundary. However, the horizontal mode is destabilized for the equilibrium with rescaled ballooning mode optimized pressure gradient (see Fig. 2, a), which is finite at the boundary. The corresponding mode is localized in the X-point vicinity and there is a kind of a beta limit for such a mode close to $\beta_{N}=4.1$ for passive stability.

\section{OUTER X-POINT: MAGNETIC SYSTEM AND SCENARIOS}

In this section some examples of magnetic systems capable of sustaining the $\mathrm{XX}$ free boundary equilibria are demonstrated. The poloidal field (PF) coils and vacuum chamber layout for the DEMO-FNS [11] are used for reference. An additional divertor coil lying in the equatorial plane is needed to generate the outer X-point. The numeric studies of the free boundary equilibrium using the SPIDER code have shown that such a coil, accompanied by two closely adjacent pushing coils, provides a very economical PF layout in terms of the sum of the PF coils' absolute currents to plasma current ratio $\sum_{i}\left|I_{\mathrm{PF}, i}\right| / I_{p}$, which is just above 1 in the case of the X-point lying close to the divertor coil (Fig. 4, $a$ ).

The farther the X-point is from the divertor coil, the larger is the $\sum_{i}\left|I_{P F, i}\right| / I_{p}$ current ratio (Fig. 4. b). Of course, a solenoid is needed to support the plasma current drive in addition to a group of the divertor coils. In preliminary scenarios a gradual increase of the divertor coil current produces the outer X-point starting from a limiter plasma inboard the vacuum vessel. Such a magnetic system looks quite simplistic and potentially provides a large volume available above and below the plasma equator, but does not seem
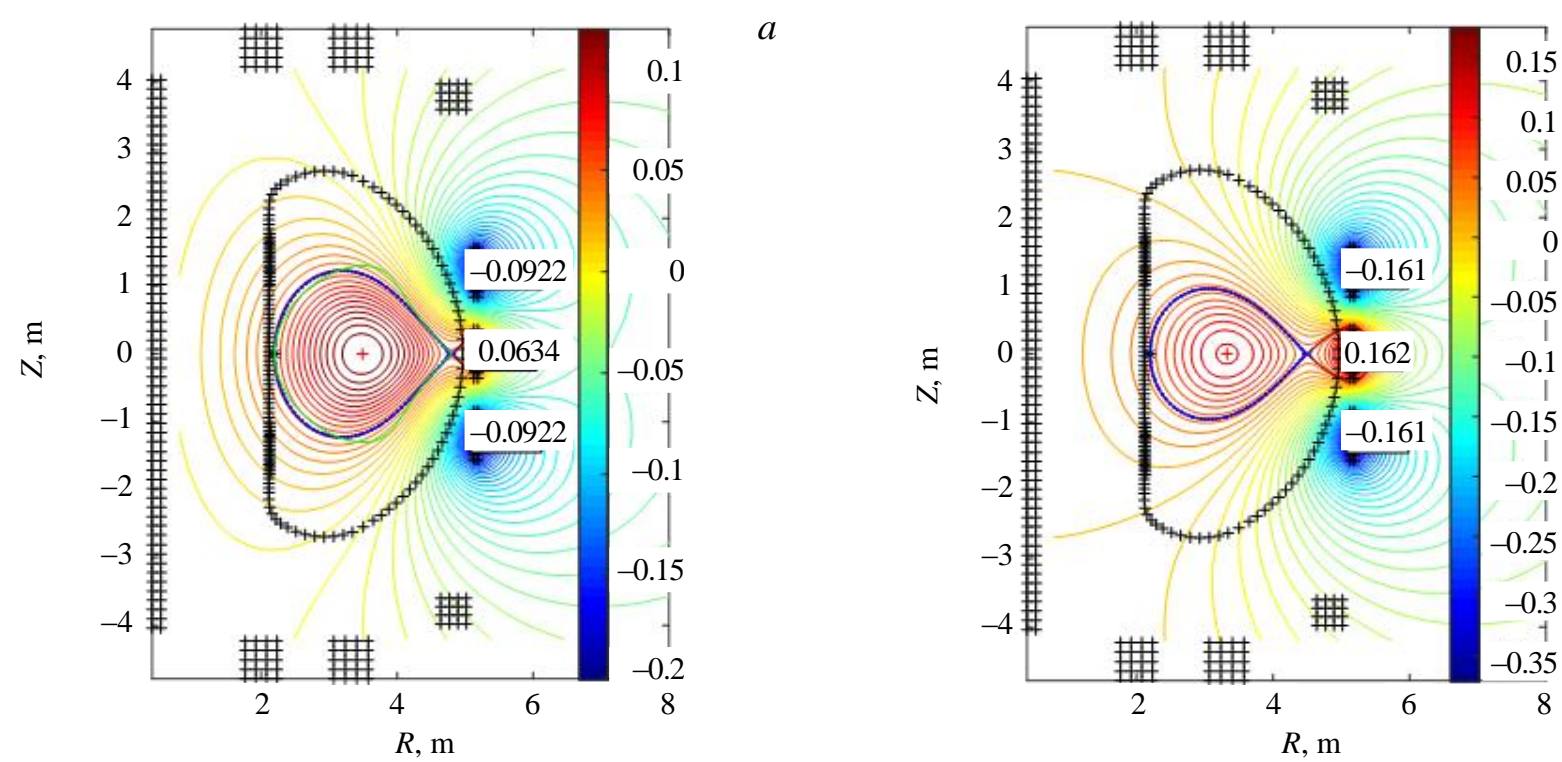

Fig. 4. Poloidal flux contours for free boundary equilibria sustained by the currents in three outboard PF coils: $a$ - plasma boundary fitted to the XX shape (green contour, $\delta=0$ ) with X-point radius $4.8 \mathrm{~m}$, current ratio $1.55 ; b-\mathrm{X}$-point radius $4.5 \mathrm{~m}$, current ratio 3.0 . Plasma current $0.16 \mathrm{MA}, \mathrm{PF}$ coil currents in MA are shown, color bar for poloidal flux in $\mathrm{Wb} /(2 \pi)$ 
compatible with neural beam injectors (NBI). More flexibility and volume would also be desirable for the divektor control. That is why an array of horizontal coils was tried out as an alternative option (Fig. 5). While being quite flexible (and also allowing snowflake divertor, Fig. 5, $c$ ) and seemingly better NBI compatible, this configuration requires much larger PF current due to divertor coils distanced farther away from the plasma. Moreover, the plasma scenario and control look more complicated. Let us note that for the case with the X-point displaced from the equatorial plane (see Fig. 5, $b$ ) not only the PF coils but also divertor structures can be removed from the beam path. More realistic scenario calculations are planned using the ASTRA/SPIDER plasma evolution code [13].
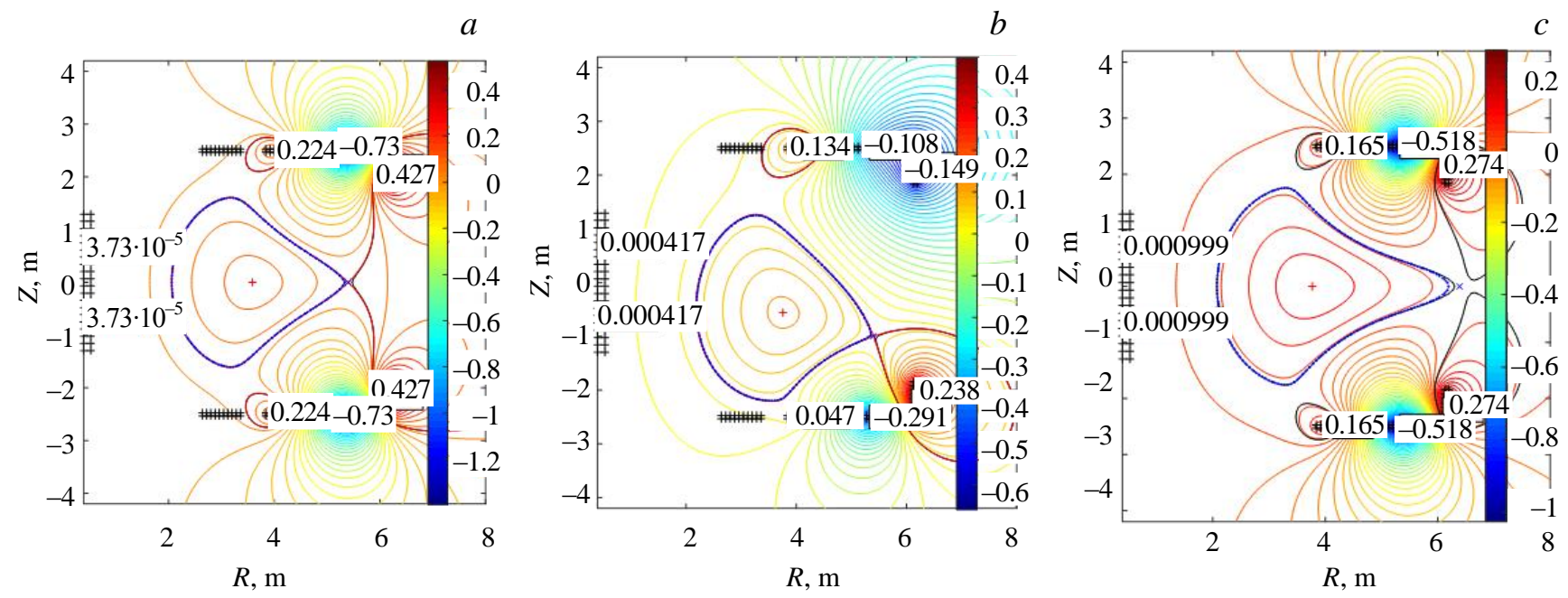

Fig. 5. Poloidal flux contours for free boundary equilibria sustained by horizontal arrays of PF coils: $a-\mathrm{X}$-point radius $5.4 \mathrm{~m}$, current ratio 17; $b-\mathrm{X}$-point coordinates $(5.4 \mathrm{~m},-1 \mathrm{~m})$, current ratio $6 ; c-\mathrm{X}$-point radius $6.4 \mathrm{~m}$, current ratio 12. Plasma current $0.16 \mathrm{MA}$, PF coil currents in MA are shown, colorbar for poloidal flux in $\mathrm{Wb} /(2 \pi)$

\section{DISCUSSION}

In terms of MHD-stability, the main advantage of the XX configurations is a robust low pedestal limit set by internal localized modes and the lack of access to the second stability region. This can give rise to soft edge plasma limits, imposed by an electro-magnetic turbulence or, at least, by much milder ELM crashes. However the second stability access is still possible in the core of an elongated positive triangularity plasma and the pressure-driven external kink limit $\beta_{N}$ exceeds 3. Axisymmetric $n=0$ modes can manifest themselves as coupled vertical/horizontal modes featuring a destabilizing pressure gradient near the edge.

Considering XX configurations as an alternative divertor solution, one can notice a simple magnetic system and possible NBI compatible flexible configurations with easier outer divertor access and better pumping conductance if the X-point is displaced from the equatorial plane. Anyway, larger outer X-point major radius for separatrix wetted area favors the power exhaust capability combined with a stationary - no ELMs - confinement. At the same time the main plasma bulk can reside in a higher B domain leaving the shaping coils in lower magnetic field region, e.g. making NbTi superconductor applicable for the shaping coils. Key remaining questions relate to energy confinement properties of the discussed configurations. As there are favorable indications for negative triangularity in terms of core confinement, the «JT-60 curse» for the confinement in XX configurations could be overcome: it might be time for the XX-experiment second try.

\section{REFERENCES}

1. Camenen Y. et al. - Nucl. Fusion, 2007, vol. 47, p. 510.

2. Austin M.E. et al. - Phys. Rev. Lett., 2019. vol. 122, p. 115001.

3. Fontana M. et al. - Nucl. Fusion, 2018, vol. 58, p. 024002.

4. Kikuchi M. et al. - Nucl. Fusion, 2019, vol. 59, p. 056017.

5. Medvedev S.Yu. et al. - Nucl. Fusion, 2015, vol. 55, p. 063013. 
6. Merle A. et al. - Plasma Phys. Control. Fusion, 2017, vol. 59, p. 104001.

7. Kikuchi M. et al. — Eur. Phys. J. H, 2018, https://doi.org/10.1140/epjh/e2018-90054-2.

8. Ozeki T. et al. - Nucl. Fusion, 1988, vol. 28, p. 1861.

9. Ilgisonis V.I., Skovoroda A.A., Sorokina E.A. — Physics of Atomic Nuclei, 2017, vol. 80, № 7, p. 1307-1312. (Original Russian Text 2016, published in Voprosy Atomnoi Nauki i Tekhniki, Seriya: Termoyadernyi Sintez, 2016, vol. 39, № 1, p. 22-29).

10. Degtyarev L., Martynov A., Medvedev S., Troyon F., Villard L., Gruber R. — Comput. Phys. Comm., 1997, vol. 103 , p. 10 - 27.

11. Medvedev S.Yu. et al. - Plasma Phys. Rep., 2016, vol. 42, p. 472-485.

12. Shpanskiy Yu.S. and the DEMO-FNS Project Team. - Nucl. Fusion, 2019, vol. 59, p. 076014.

13. Dnestrovskiy A.Yu. et al. — In: Proc. 45th EPS Conf. Plasma Phys., 2018, vol. 42A, P4.1080.

\section{AUTHORS}

Sergey Yurievich Medvedev, PhD in physics and mathematics, Leading Researcher, Keldysh Institute of Applied Mathematics RAS, 125047 Moscow, Miusskaya sq. 4, Russia; Leading Engineer, NRC «Kurchatov Institute», 123182 Moscow, pl. Academician Kurchatova 1, Russia, Medvedevsyu@ @eldysh.ru

Alexander Alexandrovich Martynov, $\mathrm{PhD}$ in physics and mathematics, Senior Researcher, Keldysh Institute of Applied Mathematics RAS, 125047 Moscow, Miusskaya sq. 4, Russia; Leading Engineer, NRC «Kurchatov Institute», 123182 Moscow, pl. Academician Kurchatova 1, Russia, Martynov22@gmail.com

Boris Vasilievich Kuteev, deputy head of the Department for Hybrid Systems, Doctor of Physics and Mathematics; NRC «Kurchatov Institute», 123182 Moscow, pl. Academician Kurchatov 1, Russia, Kuteev_BV@nrcki.r

Alexey Yurievich Dnestrovskiy, Leading Engineer, PhD in physics and mathematics; NRC «Kurchatov Institute», 123182 Moscow, pl. Academician Kurchatova 1, Russia, Dnestrov0@gmail.com

Vladimir Victorovich Drozdov, PhD in physics and mathematics, Scientific Consultant, Tokamak Energy Ltd, 173 Brook Drive Milton Park, Oxfordshire OX14 4SD, United Kingdom, VVDrozdov0712@gmail.com

Received 15 January 2021

Revised 16 March 2021

Accepted 25 March 2021

Problems of Atomic Science and Technology Ser. Thermonuclear Fusion, 2021, vol. 44, issue 2, pp. 15-20 